\title{
Archaeological applications of resistivity and magnetic methods at Fort Wilkins State Park, Michigan
}

\author{
Charles T. Young* and David R. Droege*
}

\begin{abstract}
Geophysical measurements were conducted to locate building sites at a nineteenth-century fort in Michigan. The survey area, Fort Wilkins, was built during the copper boom of the 1840 s and is located at the tip of the Keweenaw Peninsula in the Upper Peninsula of Michigan. Resistivity and magnetic surveys were conducted over the locations of former privies, a guard house, a carpenter house, and a blacksmith shop. The resistivity surveys were made using a half-Schlumberger array with electrode spacings of $0.3,0.6,1.0,1.5$, and $2.0 \mathrm{~m}$. A masonry foundation and the privies are indicated by high-low resistivity pairs. Analog modeling was used to create anomalies similar to those seen over the privies. Measurements of the vertical magnetic gradient yielded anomalies which are associated primarily with modern objects.
\end{abstract}

\section{INTRODUCTION}

In the 1840 s, a copper boom attracted miners to Michigan's Keweenaw Peninsula. Fort Wilkins was built to maintain law and order in the copper district and to serve as a buffer between the miners and resident Chippewa Indians. The location of Fort Wilkins is shown in Figure 1. The fort was garrisoned by federal troops from 1844 to 1846 and was reoccupied from 1867 to 1870 . In 1923 the property became a Michigan state park, and the fort was restored under management of the Michigan Department of Conservation. Today, 16 of the original 23 buildings survive. Sites of seven former buildings identified by historical research and photographs and maps await archaeological investigation. Fort Wilkins park historian Thomas G. Friggins and Michigan Technological University archaeologist Patrick Martin encouraged application of geophysical techniques to locate the foundations of the missing structures as a guide for future archaeological investigations.

Standard geophysical techniques, especially magnetics and resistivity, have been used at very close stations as an aid in archaeological excavations (Carr, 1982; Tite, 1972). The suc- cess of these methods is dependent upon the contrast in physical properties between the target and the background. Sites should be tested on a case-by-case basis to establish which geophysical methods, if any, might be successful. Thus, the preliminary resistivity and magnetic measurements described here were conducted to determine whether these methods could be used in this area to detect the building sites. These surveys were conducted by the Field Geophysics class of Michigan Technological University during the summer of 1984 , at the suspected sites of two privies, a guard house, a carpenter shop, and a blacksmith shop (Figure 2).

\section{PROCEDURE}

The resistivity surveys were made with an ABEM SAS 300 Terrameter. The meter reads resistance (V/I) directly in ohms, and the values are converted to apparent resistivity by multiplying the resistance by the appropriate geometry factor for the array (Zohdy et al., 1974). The resistivity meter was connected to a small, fixed array of five current and two voltage electrodes mounted on a $2 \mathrm{~m}$ long plastic pipe. Electrode separations were selected to create a half-Schlumberger array. The potential electrodes, termed $\mathrm{M}$ and $\mathrm{N}$, were separated by 0.2 $\mathrm{m}$. The local current electrodes were present at distances of $0.3,0.6,1.0,1.5$, and $2.0 \mathrm{~m}$ from the midpoint of the potential electrode pair and could be selected with a rotary switch. This distance is termed AO. The array is essentially the same as a conventional Schlumberger array with one current electrode placed a distance away from center, thus effectively at infinity. The half-Schlumberger array was chosen for two reasons. First, it is necessary to move or change only one electrode to conduct a sounding at an individual site. Second, a greater $\mathrm{AO}$ value can be accommodated with a half-Schlumberger array on a given length of plastic pipe.

Mathematical models show that for flat layers the response of an array is a weighted average of the earth resistivities under and near the array, and that the sensitivity to deeper material increases as the electrode separation increases (as AO increases for the half-Schlumberger array). Zohdy et al. (1974) cautioned against making any direct comparison between array spacing and depth of probing; the ability to detect objects at depth depends upon resistivity contrasts between the target and the surrounding material, and upon the masking 
effect of inhomogeneities. The apparent resistivities reported are simply given as a function of the AO spacing between the center of the potential electrodes and the current electrode $\mathrm{A}$.

In all cases, the array was oriented north to south. The local current electrodes on the plastic pipe were oriented south for the privy survey and north for other surveys. The reference current electrode was placed at a distance of approximately $50 \mathrm{~m}$ from the nearest survey boundary. All data were acquired along parallel survey lines spaced $1 \mathrm{~m}$ apart. The station spacing along a given survey line was $1 \mathrm{~m}$, except where otherwise mentioned.

The magnetic survey was conducted using a Geometrics UNIMAG G-816 proton precession magnetometer. This instrument has an accuracy of $1 \mathrm{nT}$ when the magnetometer head is separated from the electronics package, but the accuracy is degraded to about $10 \mathrm{nT}$ for this survey since the magnetometer head was attached to the package. Readings were taken at heights of $0.5 \mathrm{~m}$ and $1.5 \mathrm{~m}$, at $1 \mathrm{~m}$ intervals along the same traverses used in the resistivity survey. Three magnetometer readings were taken at each position and averaged.

\section{DATA PREsentation}

Contour maps were made of apparent resistivities for all electrode spacings. The maps presented are the ones that show the best correspondence with known or suspected archaeological features.

The magnetic-field gradient was found by subtracting the $1.5 \mathrm{~m}$ field strength from that found at $0.5 \mathrm{~m}$. Use of the gradient, rather than the total field, emphasizes the shallow sources and reduces regional gradients and removes drift. Deeper sources have smaller gradients.

Our surveys were referenced to corners of existing buildings. The locations of the former buildings indicated on our data plots were determined by measuring from buildings indicated on an old map of the fort (Anonymous, 1924). We estimate that the locations determined from this map may be in error by as much as $1 \mathrm{~m}$, and assert that location discrepancies between the former building locations determined from the old map and the locetion of associated geophysical anomalies be resolved in favor of the geophysical survey.

\section{FACTORS AFFECTING DATA}

The resistivity method is expected to be useful in detecting building foundations and excavations. The building foundations are expected to be resistivity highs, and excavations may be resistivity highs or resistivity lows depending on the water content and degree of compaction of the fill compared to the surrounding medium.

There are several factors that can determine whether archaeological features can be seen with resistivity methods (Carr, 1982).

1. Soils vary in the chemical and physical characteristics which determine resistivity. These fluctuations can effectively hide the anomaly produced by an object.

2. There are many natural features that cannot be differentiated from archaeological features. For example, if the composition is similar, foundations may be indistinguishable from rocks in the soil.
3. The resistivity of a soil depends upon the moisture content and, to a lesser extent, the degree of soil compaction.

4. A shallow object will have a larger effect on measured resistivity than the same object at greater depth.

5. The clarity of a plot in displaying the location of a discontinuity can be affected by the contrast in the resistivities of the two media on either side of the discontinuity, the electrode configuration and separation, and/or the angle that the array makes with the discontinuity.

Similar principles apply to magnetic surveys; low magnetic contrasts between objects and the surrounding soil, varying soil composition, and an increased depth of burial can obscure magnetic anomalies. Magnetic anomalies are expected to be

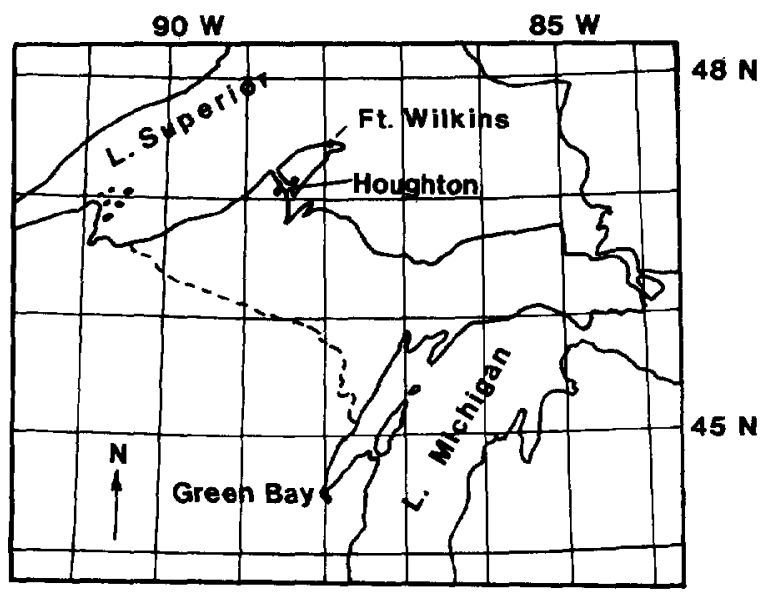

FIG. 1. Location map indicating Fort Wilkins.

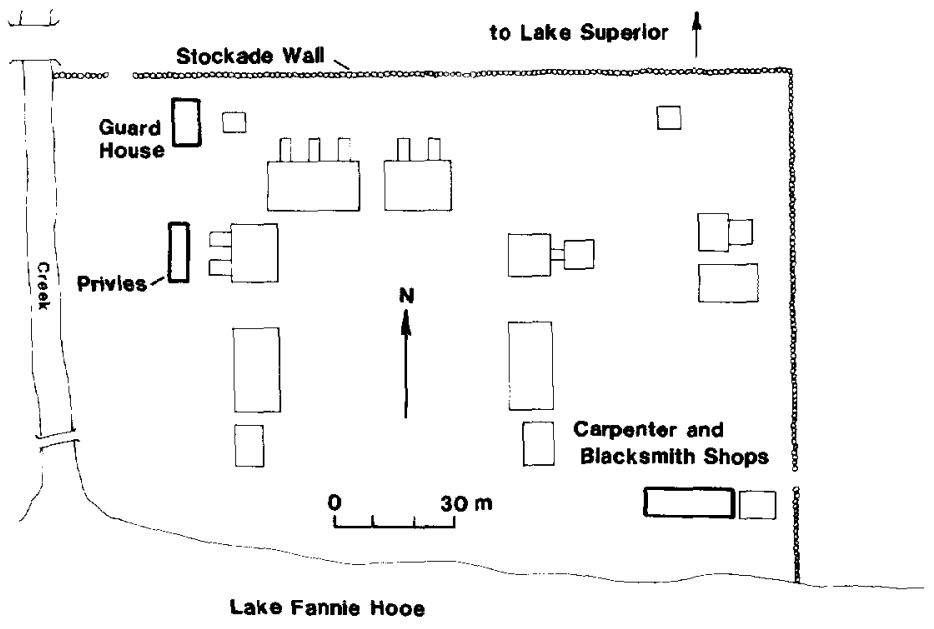

FIG. 2. Detailed site location within Fort Wilkins. The Lake Superior shoreline is approximately $1 \mathrm{~km}$ due north and strikes east to west. 
due to iron objects, burned or fired objects which have acquired new remanent magnetization, or a change in susceptibility resulting from weathering which would occur in excavations, earthworks, or garbage piles.

\section{SITE DESCRIPTIONS AND RESULTS}

The following conditions are common to all sites in the fort and may have an influence on the surveys.

1. The soil consists of 15 to $20 \mathrm{~cm}$ of fill, underlain by 1 to $2 \mathrm{~m}$ of pebbly soil. This soil overlies Copper Harbor conglomerate, which outcrops within the park in nearby privies, cellars, and in Fanny Hooe Creek. The resistivity and magnetic properties of the conglomerate are expected to be heterogeneous. This conglomerate consists of "rounded, cobble-to-small boulder-sized clasts with a matrix of (sand) cemented with iron oxides" (Bornhorst et al., 1983). The clasts are predominantly felsic volcanics.

2. Native copper has been found in the area and could give rise to conductive anomalies.

3. Iron stoves were probably used in heating the guard house, carpenter shop, and blacksmith shop. Therefore, stove parts and other iron artifacts should be easily detected in a magnetic survey. In addition, if a permanent forge occupied the blacksmith shop, an anomaly may be present due to thermal remnant magnetism in the forge bricks.

Resistivity and magnetic contour maps for each site are presented in Figures 3 to 5 .

\section{Privies}

The survey location for the privies is shown on the map of Fort Wilkins in Figure 2. The northernmost privy was excavated in 1977. It contained faunal remains, seeds, glassware, ceramics, and some small metal objects. Its dimensions were $1.7 \mathrm{~m}$ east to west by $2.1 \mathrm{~m}$ north to south by $1.2 \mathrm{~m}$ deep. The bottom $0.6 \mathrm{~m}$ is bounded by a $\log$ cribbing that was left in place after excavation. The soil removed from the hole was replaced after screening.

A map of the fort (Anonymous, 1924) indicates a second privy located approximately $3 \mathrm{~m}$ south of the one that was excavated. A utility map from the 1960 s indicates a metal water pipe lying northwest through the survey area. The exact location of the pipe cannot be accurately determined from the map.

Data contours for the privy site are shown in Figure 3. The apparent resistivity for $\mathrm{AO}=1.5 \mathrm{~m}$ is displayed in Figure $3 \mathrm{a}$, a pseudo-depth section $\mathrm{Z}-\mathrm{Z}^{\prime}$ is shown in Figure $3 \mathrm{~b}$ and the magnetic gradient is shown in Figure $3 \mathrm{c}$.

Prominent anomalies are labeled A, B, C, and D in the plots of Figures $3 \mathrm{a}, 3 \mathrm{~b}$, and $3 \mathrm{c}$ and are referred to by these letters. Anomalies $\mathrm{A}$ and $\mathrm{C}$ appear as high-low resistivity pairs with the high resistivity to the north (right). This high-low couple is an artifact of the array, as illustrated by modeling (to be discussed later). These anomalies are present at nearly all electrode spacings, implying that the body causing it has a relatively large vertical dimension. The anomalies at $\mathbf{A}$ and $\mathbf{B}$ are associated with the privy sites. The privy at $\mathbf{A}$ was excavated in 1977 and refilled, and has a higher apparent resistivity than the one at $\mathrm{B}$. If the disturbed soil is dry and uncompacted, it may account for the higher resistivity at $\mathrm{A}$ compared to $\mathrm{B}$. Figure $3 \mathrm{c}$ indicates small magnetic anomalies of magnitude 10 $\mathrm{nT} / \mathrm{m}$ or less at both privy locations. These anomalies may be due to realignment of the relatively scarce magnetite in the refilled soil. The large magnetic field gradient anomaly at $D$ is most likely due to an iron water pipe just east of the site.

\section{Guard house}

Apparent resistivity contours at the guard house for $\mathrm{AO}=0.3 \mathrm{~m}$ are shown in Figure $4 \mathrm{a}$, and magnetic gradient contours are shown in Figure $4 \mathrm{~b}$. The survey boundary should have been extended beyond the building walls but was not, due to incomplete information available at the time the survey lines were laid out.

The guard house was $7.6 \mathrm{~m}$ east to west by $9.5 \mathrm{~m}$ north to south. It was constructed of logs caulked with mortar. A 1912 photograph indicates that the guard house had been dismantled down to the foundation. By probing, the foundation was found to be $45 \mathrm{~cm}$ wide and to lie $12 \mathrm{~cm}$ below the ground surface. It consists of "uncoursed stone rubble masonry" (T. Friggins, pers. comm.) and is likely to be Copper Harbor conglomerate. Thus, it is likely that the foundation walls would be electrically resistive compared to the surrounding soil.

Anomalies on the apparent resistivity and the magnetic gradient plots are labeled $G$ through $J$ in Figures $4 a$ and $4 b$, and are discussed below.

Elongated anomalies $G$ and $H$ represent the north and east sides of the foundation on the resistivity plot. These anomalies are largest for $\mathrm{AO}=0.3 \mathrm{~m}$ and gradually disappear at larger electrode spacings.

The linear low-resistivity anomaly I lies north to south just inside of the resistivity high $\mathbf{H}$. Anomalies $\mathbf{I}$ and $\mathbf{J}$ are prominent on the $A O=0.3 \mathrm{~m}$ plot. Both are present through $\mathrm{AO}=1.0 \mathrm{~m}$, but they become weak and harder to identify on the other plots. J lies inside the western wall, and I lies inside the eastern wall.

An increase in magnetic gradient toward the east, as shown in Figure $4 \mathrm{~b}$, is probably due to an existing building with a metal roof $6 \mathrm{~m}$ east of the eastern boundary of the survey. Low magnetic field gradients indicate that there are probably no sizable iron artifacts within the guard house foundation. The cause of the other anomalies with amplitudes 10 to 40 $\mathrm{nT} / \mathrm{m}$ may be due to smaller iron artifacts or to magnetic susceptibility variations in the soil. There appears to be no pattern of magnetic anomalies associated with the building foundation.

The eastern foundation line of the guard house is indicated by parallel bands of high and low resistivity. The high resistivities are probably caused by building stones. The northern foundation line is indicated by a high-resistivity region. The difference in response between the eastern and northern foundation lines may be due to the fact that the array was deployed parallel to the eastern wall, but perpendicular to the northern wall. The low-resistivity region adjacent to the foundation stones is best detected by an array extended parallel to the foundation because all of the electrodes would be in the low-resistivity region. It is unclear what could give rise to the small resistivity anomalies within the guard house. 


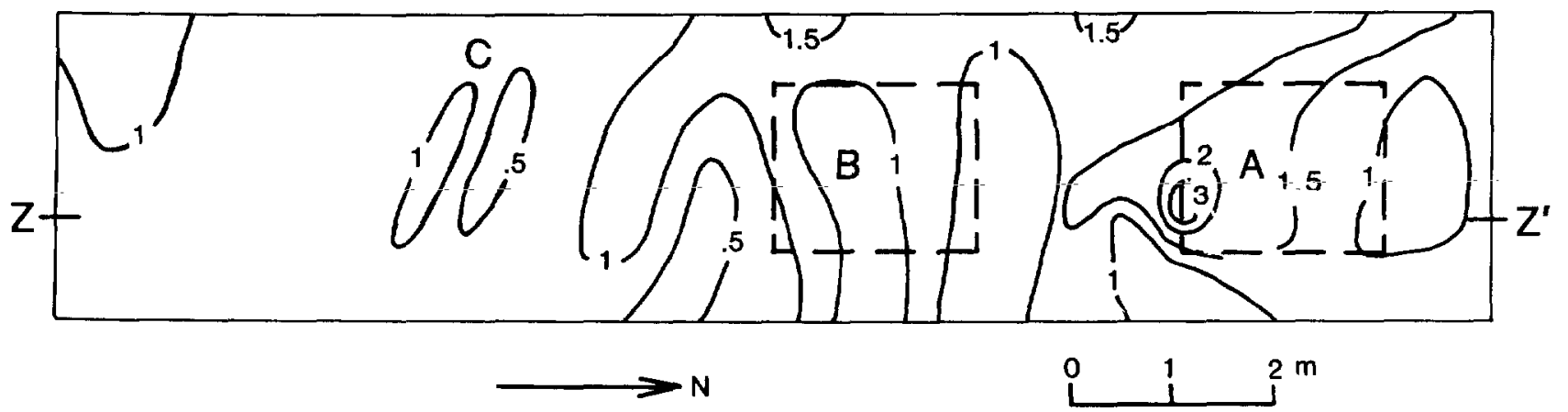

FIG. 3a. Privy data. Apparent resistivity contours for $A O=1.5 \mathrm{~m}$. The station spacing is $1 / 2 \mathrm{~m}$ in the north to south direction and $1 \mathrm{~m}$ in the east to west direction, except for the westernmost edge of the survey where the north to south station spacing is $1 \mathrm{~m}$. Contours are kilohm-m. The privy locations are indicated by dashed lines (Anonymous, 1924). The resistivity data are plotted directly under the center of the potential electrode pair in all figures. The privy locations coincide with high-low resistivity pairs $\mathrm{A}$ and $\mathrm{B}$. The source of anomaly $\mathrm{C}$ is unknown.

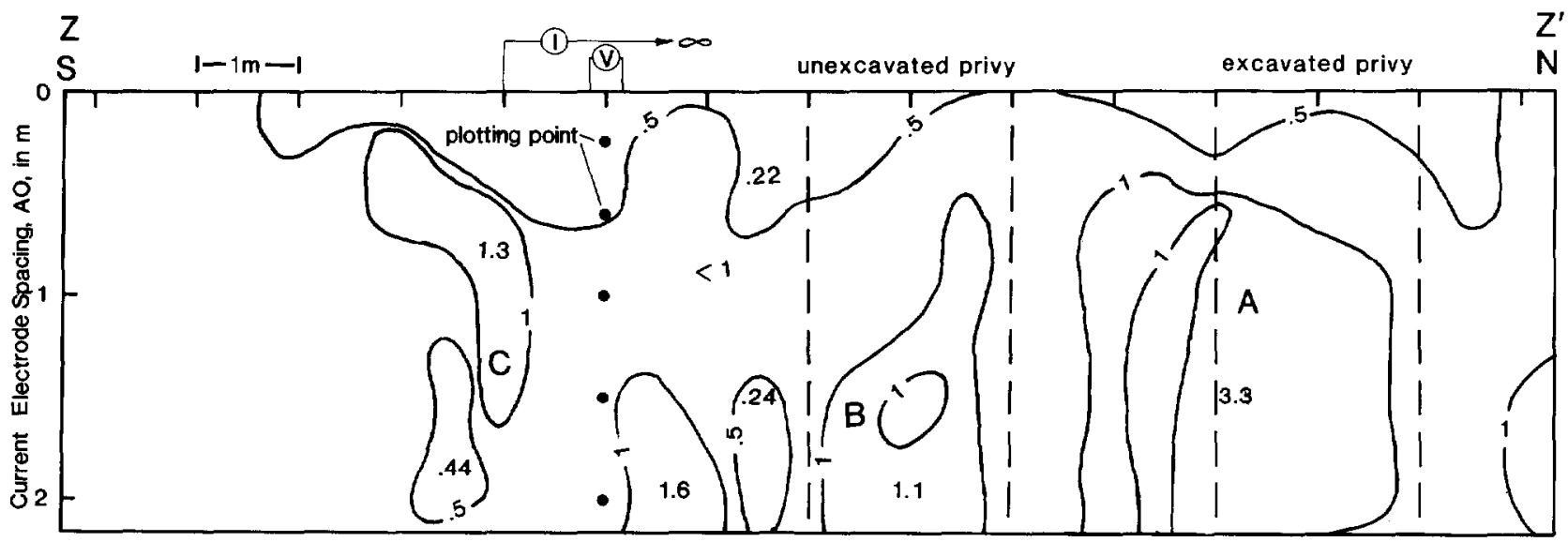

Fig. 3b. Pseudo-depth section $\mathrm{Z}-\mathrm{Z}^{\prime}$. The array configuration and plotting convention are indicated at the top of the figure. Anomalies A, B, and C are strongest at depths 1.0 to $1.5 \mathrm{~m}$. Extreme resistivity values are indicated inside contour closures.

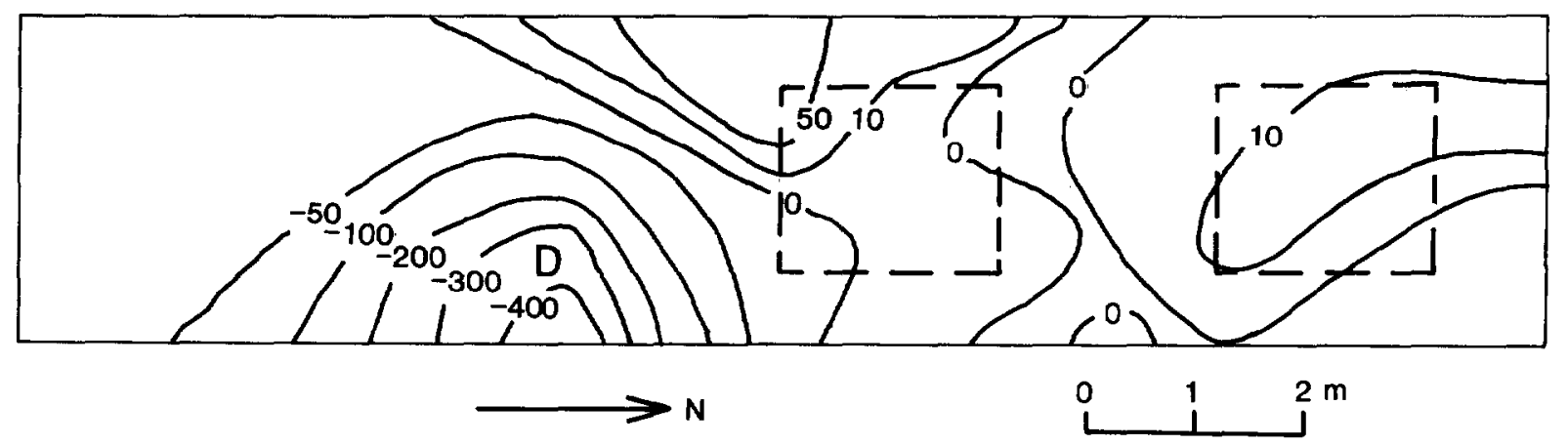

FIG. 3c. $N_{\text {. }}$ gnetic gradient contours. The units are nanoteslas per $m$, positive downward. The contour interval is irregular to indicate the weak anomalies over the privies. Anomaly D is suspected to be caused by a water pipe just east of the site. 
Surprisingly, the southern foundation line of the guard house shows small response on the resistivity contours. Its only indication is distortion in the $1 \mathrm{k} \Omega \cdot \mathrm{m}$ contours. The section on modeling shows that the magnitude of anomalies detected with the half-Schlumberger array are very dependent upon the location of the potential electrode relative to the anomalous body. This effect could account for the weaker anomaly for the south foundation wall. For example, the potential electrode pair may have been very close to or on top of the foundation at the north wall, whereas at the south wall, the wall may have been more distant from the potential electrodes.

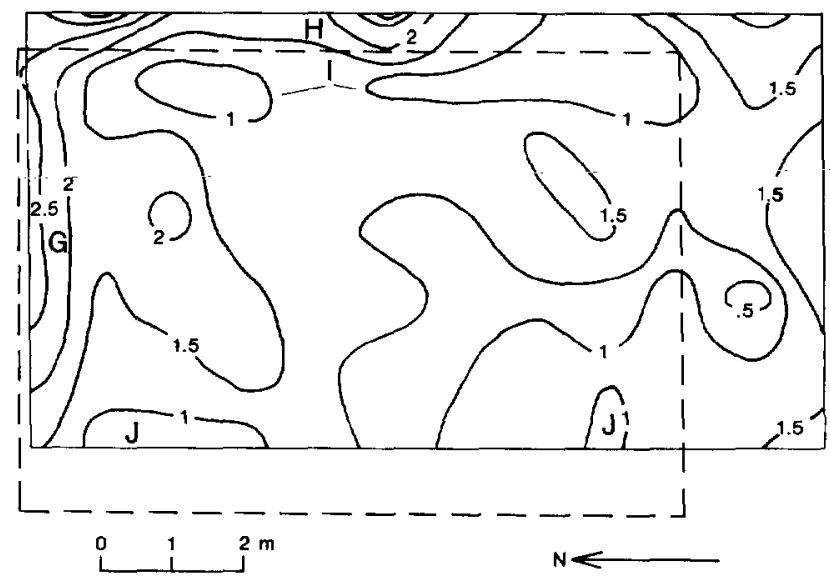

FIG. 4a. Guard house data. Apparent resistivity contours at $0.3 \mathrm{~m}$. The units are kilohm-m. The dominant features are linear resistivity highs $G$ and $H$ which are associated with building foundation.

\section{Carpenter shop and blacksmith shop}

Dimensions of the carpenter shop were $6 \mathrm{~m}$ east to west by $4.5 \mathrm{~m}$ north to south. According to the $1924 \mathrm{map}$, it was about $3 \mathrm{~m}$ west of the bakery. The shop was constructed of logs caulked with mortar. There is no evidence of a stone foundation; therefore, it is assumed the shop had a $\log$ sill laid directly upon the ground.

No written descriptions of the dimensions of the blacksmith shop exist, but the 1924 map shows it was similar in size to the carpenter shop. Existing reports indicate that blacksmith work was done only occasionally. Accordingly, the blacksmith shop

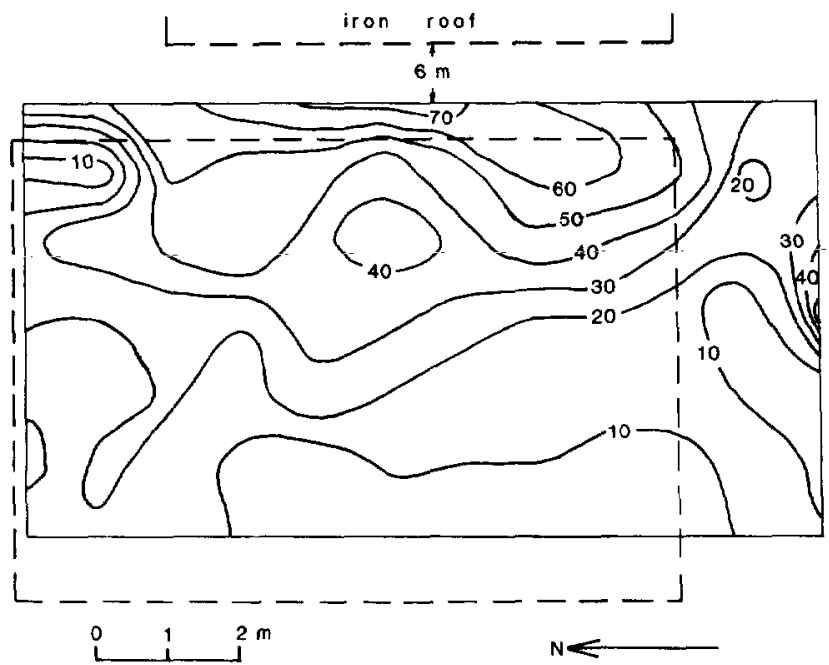

FIG. 4b. Guard house data. Magnetic gradient contours. The units are nanoteslas per $m$, positive downward. The data are dominated by a regional gradient due to the iron roof of a nearby building.

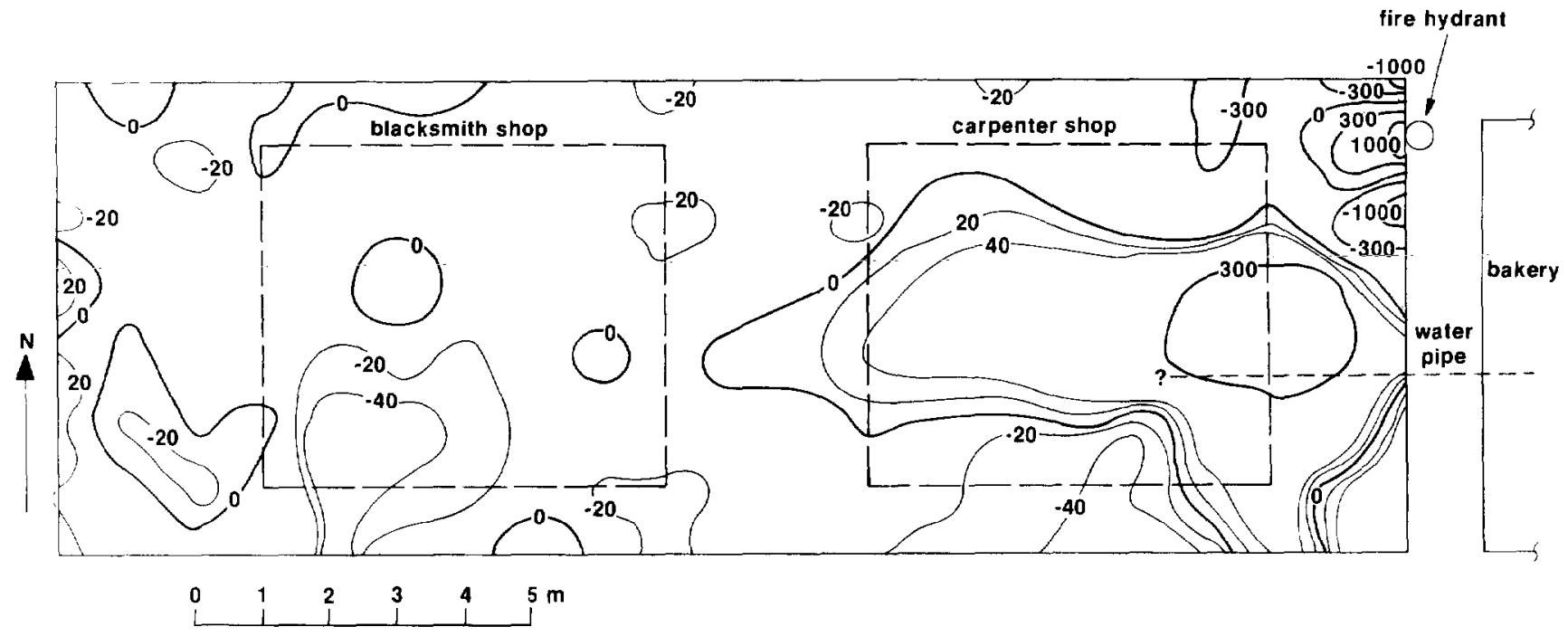

FIG. 5a. Carpenter shop and blacksmith data. Magnetic gradient contours. Units are nanoteslas per m, positive downward. Irregular contour intervals are used to show the weaker anomalies in the western portion of the survey. 
was converted into a second carpenter shop by 1870 .

The carpenter and blacksmith shop walls were expected to have minimal resistivity contrast because of the lack of a foundation. A magnetic survey would be likely to detect iron artifacts such as nails, lost tools, or scrap metal.

The location of the carpenter and blacksmith shop survey is shown on the map of Figure 2. The approximate outlines of the buildings are shown on the magnetic gradient map in Figure 5a. The strong magnetic anomaly at the northeast corner of the survey is caused by the fire hydrant indicated in Figure 5a. Iron piping is attached to the hydrant from beneath the bakery and is probably the source of the anomaly just south of the fire hydrant. Another iron pipe, lying east to west in the eastern portion of the survey, was observed in the basement of the bakery protruding out of the basement wall. The broad anomaly under the carpenter shop outline is probably caused by this pipe.

Because of the nearly complete lack of magnetic anomalies over the blacksmith shop as compared to the carpenter shop, the resistivity measurements were made only over the latter.

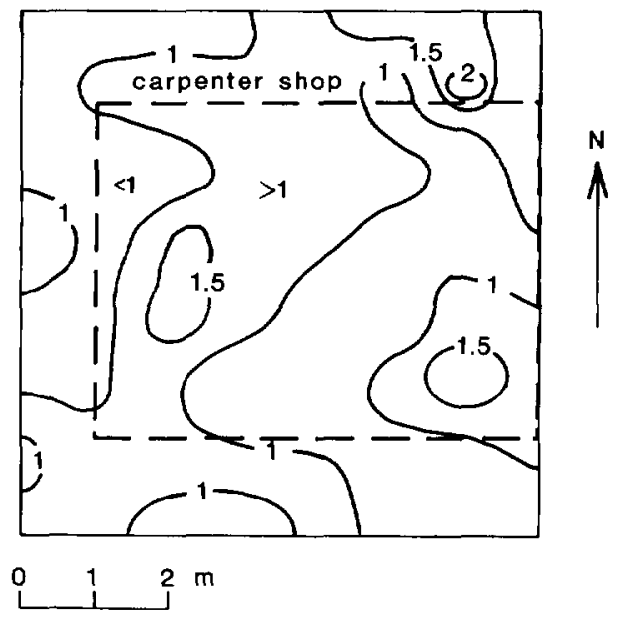

FIG. 5b. Carpenter shop and blacksmith data. Apparent resistivity contours for $\mathrm{AO}=0.3 \mathrm{~m}$ for carpenter shop. Units are kilohm-m. The dashed line indicates the approximate location of the walls of the carpenter shop, estimated from the old map of the fort (Anonymous, 1924).

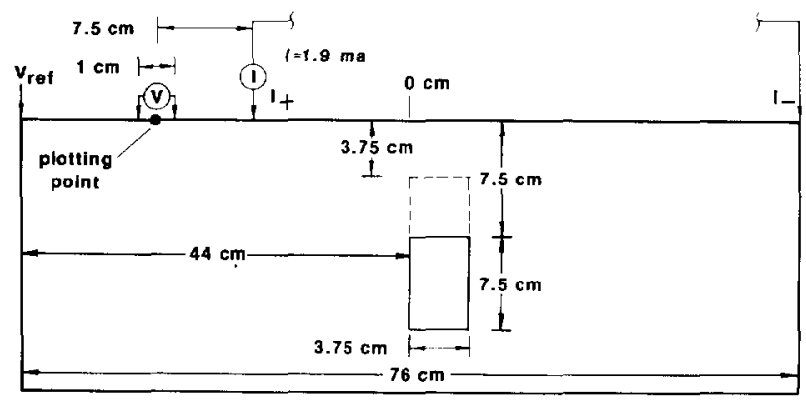

Fig. 6. Dimensions of analog model and electrode configurations. The top of the body causing the anomaly is set at one of two depths and the bottom of the body is fixed. The current was $1.9 \mathrm{~mA}$.
The apparent resistivity contours over the carpenter shop are shown in Figure 5b for an $\mathrm{AO}$ electrode spacing of $0.3 \mathrm{~m}$. Resistivity fluctuations are small in the survey area. Weak linear features in the contours coincide with the building outline.

\section{MODELING}

The occurrence of anomalies consisting of high-low resistivity pairs raised the question of the response of the halfSchlumberger array to 2-D and 3-D bodies. Master curves for this array deployed over such bodies are not generally available in geophysical literature. Lacking published curves, we conducted analog modeling to demonstrate the response of this array. In the model, the host rock is simulated by a sheet of conductive paper, a conductive body is simulated by conductive paint (nickel colloid), and a resistive body is simulated by a cutout in the paper. The moving electrodes are sharpened machine screws mounted on a rigid plastic bar. Dimensions of the model are given in Figure 6. This type of model represents an earth of constant cross-section and infinite extent into and out of the conductive paper. The rectangle of conductive paint represents an infinitely long body of rectangular cross-section, and the electrodes represent line current and potential electrodes.

Even though the geometries of the model and field situation are not identical, we expect several similarities.

1. The electrical reflection coefficients computed from the contrast between the host and the conductor or insulator will be preserved in the model and in the 3-D earth; thus the sign of an anomaly will be the same as in the earth.

2. The decay of the magnitude of an anomaly with lateral distance is present in both the model and the earth, although the rate of decay with distance is different. An anomaly decays more slowly with distance in the analog model because potential due to an infinitesimal source varies with $\log (1 / r)$ in two dimensions rather than $(1 / r)$ in three dimensions.

Model measurements of current and voltage were made with 3-1/2 digit digital voltmeters, and the current was obtained from a laboratory power supply. Individual data were somewhat erratic, presumably because of irregularities in the edge of the conductive paper. To reduce the effect of the irregularities, data were taken at very close intervals $(0.5 \mathrm{~cm})$ and the results smoothed by hand. We estimate the error in our curves to be about 5 percent of the maximum value for the stronger anomalies and 15 percent for the weaker anomalies, compared to what we would obtain with perfectly uniform conductive paper.

A set of model responses is presented in Figure 7. Five cases were modeled. Curves a and $b$ are for resistive bodies, $\mathrm{c}$ and $\mathrm{d}$ are for conductive bodies. The depth to the top of the body was cither $\mathrm{AO}$ or $0.5 \mathrm{AO}$. For curve e, the potential electrode pair was replaced with a single moving potential electrode and a reference electrode at the curner of the conductive paper. For all curves, the quantity plotted is the potential measured with the body in place divided by the potential measured before the body was emplaced. This quotient is the same as the ratio of apparent resistivities with and without the body. The data are discussed for the array moving from left to right 


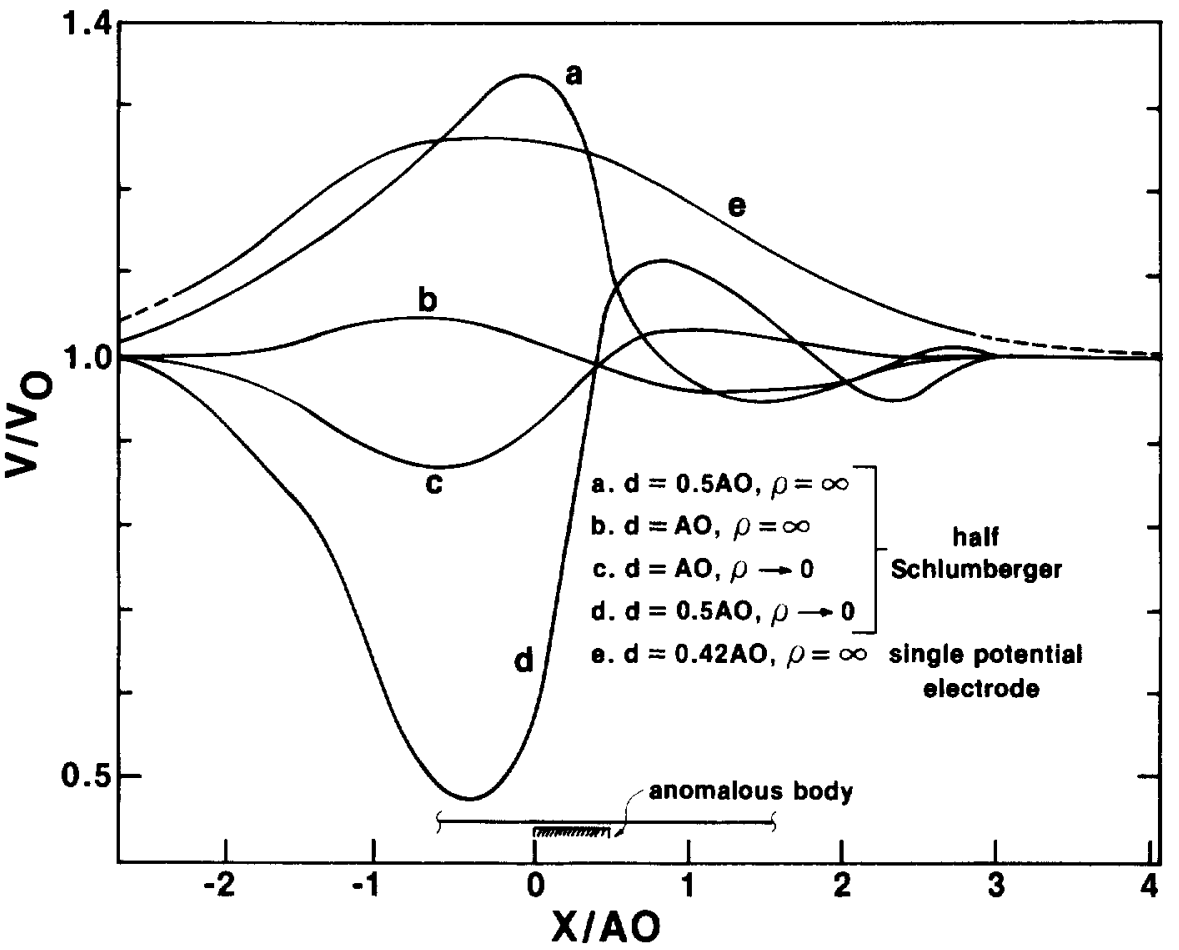

FIG. 7. Model profile data for half-Schlumberger array (curves a, b, c, and d) and single potential array (curve e). The reference potential electrode for $e$ is located on the positive end of the model at the opposite end of the current electrode. Model data were sampled every 1 or $0.5 \mathrm{~cm}$, with closer spacings used where voltage varied rapidly with position. For curves a, b, c, and d, the potential is plotted midway between the potential electrodes. For curve e, it is plotted at the moving potential electrode. The symbol $d$ in the key refers to the depth to the top of the anomalous body:

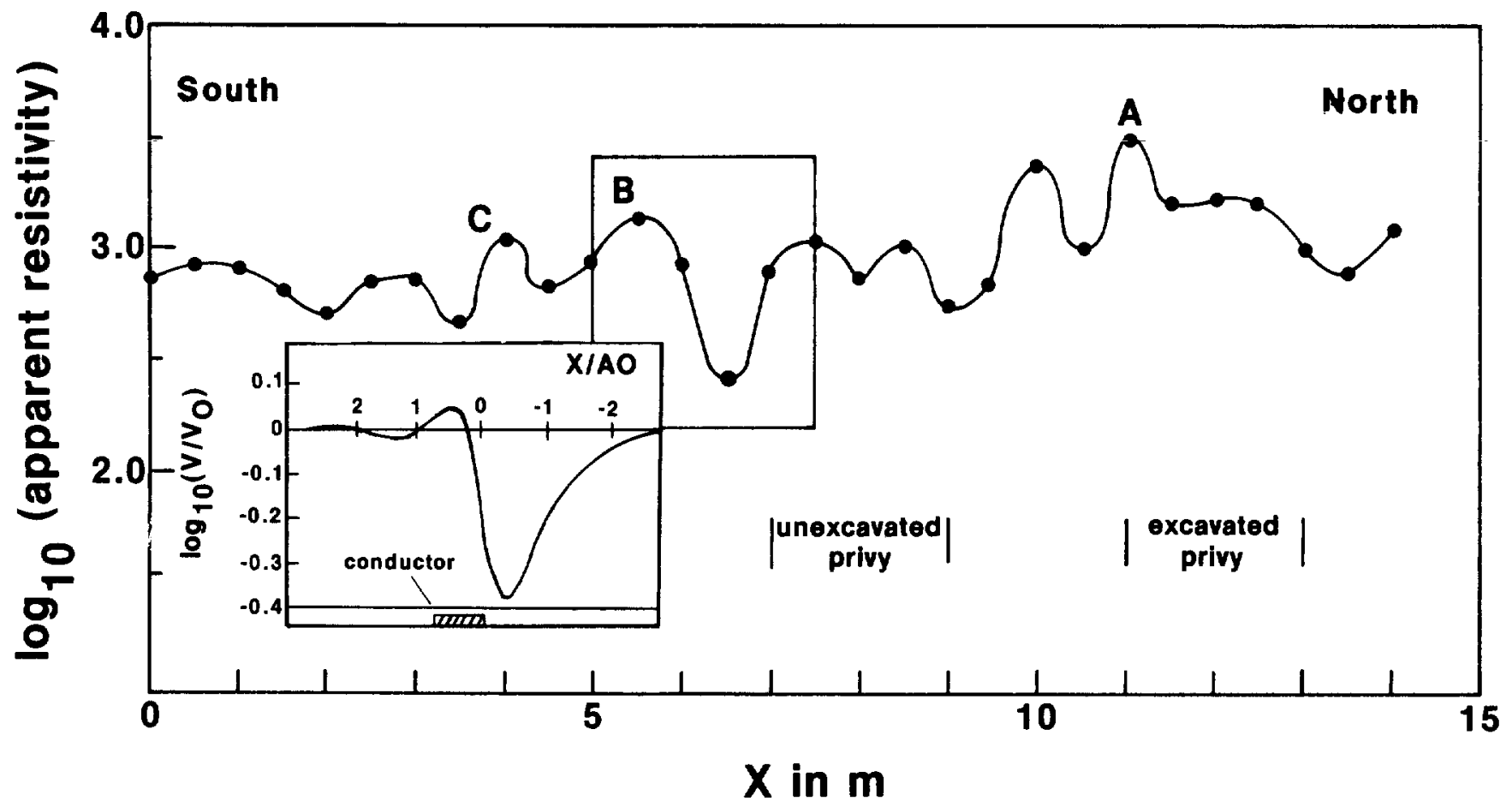

FIG. 8. Apparent resistivity at $\mathrm{AO}=1.5 \mathrm{~m}$, for profile $\mathrm{Z}-\mathrm{Z}^{\prime}$ on Figures $3 \mathrm{a}$ and $3 \mathrm{~b}$. Inset shows curve $\mathrm{d}$ from Figure 7 for comparison. The vertical and horizontal scales for the inset have been chosen for a good match between the model and the field data. The horizontal axis on curve e has been reversed to make the current electrode directions agree between model and data. 
on the model with the current electrode leading. Cases a, b, c, and $\mathbf{d}$ all show anomalies with a primary lobe having the same sense as the resistivity contrast of the body causing it. Following the primary lobe is a weak secondary lobe of the opposite sense. For the shallower bodies, $\mathrm{d}=0.5 \mathrm{AO}$, a small tertiary lobe is also present with the same sense as the primary lobe. Presumably, this tertiary lobe is present for $\mathrm{d}=\mathrm{AO}$ but was too weak to detect.

A conductive body produces a primary lobe with low poiential difference and a resistive body produces a primary lobe with a high potential difference. Profiles $a, b, c$, and $d$ all have a secondary lobe with the opposite sense to the primary lobe. The primary lobe is strongest just before the current electrode encounters the closest edge of the body. The transition from the primary lobe to the secondary lobe occurs when the closest edge of the body is under the midpoint of the line joining the potential pair and the current electrode.

The final curve, e, uses a single potential electrode with a distant reference. This array is constructed from the original array using only the outermost two electrodes. This profile indicates a single anomaly with the same sense as the resistivity contrast of the body. The anomaly is approximately the same width as the combination of primary, secondary, and tertiary lobes of the half-Schlumberger array, and is a maximum when the body is between the current and potential electrodes.

Figure 8 compares the apparent resistivities at $\mathrm{AO}=1.5 \mathrm{~m}$ along line $\mathrm{Z}-\mathrm{Z}^{\prime}$ (Figures $3 \mathrm{a}$ and $3 \mathrm{~b}$ ) with analog model profile $\mathrm{d}$ in Figure 7. Both are displayed on a logarithmic scale. The similarity between- the two suggests that the unexcavated privy at this location is conductive. Similarly, the excavated privy appears to be a pair of resistive anomalies.

The model shows that the conductive body is approximately centered on the zero crossing between the primary and secondary lobes of the anomaly. In the field data within the box on Figure 8 the zero crossings or points of maximum slope are offset from the privy locations by about $1 \mathrm{~m}$. This is about the same value as the error expected in the privy location, and as mentioned earlier, we are inclined to trust the geophysical measurements rather than the privy locations estimated from the old map.

\section{SUMMARY}

Magnetic and resistivity geophysical surveys were conducted over building sites at Fort Wilkins State Park. The resistivity survey found anomalies which correlated with building foundations or excavations. The magnetic survey found anomalies which correlated chiefly with water pipes.

Probable locations of two walls of the guard house and the locations of the privies could be determined using the resistivity method. The perimeter of the carpenter shop is indicated by weak linear contours. There is no evidence of a stone foundation; thus the anomaly may be due to an increase in the soil compaction from the weight of the log walls.

Analog modeling indicates that an infinitely long conductor with a rectangular cross-section produces anomalies on a halfSchlumberger array which have a primary conductive lobe and a small secondary resistive lobe. A resistive body produces a similar anomaly with the opposite sense. An array with a single moving potential electrode and a reference at infinity produces a single anomaly with the same resistivity contrast as the body causing it. This array requires one more long wire than the half-Schlumberger array, but the simplicity achieved in interpreting the data is clearly worth the extra effort in the field.

The dominant magnetic anomalies were due to water pipes and an iron roof. A weak anomaly is associated with one of the privy sites, but any anomalies associated with building foundations must be beneath our measurement noise level.

The sensitivity of the magnetic methed could possibly be increased by measuring fields at a height of $10 \mathrm{~cm}$ instead of $50 \mathrm{~cm}$ and by attaching the magnetometer sensor to a tripod or staff. The sensitivity to extremely small objects such as pebbles, hairpins, and shoe nails then becomes greater.

We concluded that the resistivity method was more useful than the magnetic method for mapping building foundations. Even though the magnetic maps were dominated by modern objects in our tests, the magnetic mapping should be routinely conducted along with resistivity because of its success in other archaeological investigations and because of the likelihood of finding iron artifacts.

\section{ACKNOWLEDGMENTS}

The authors thank the following for their contributions: Michigan Department of Natural Resources personnel for permission to conduct the survey and for their cooperation; the Geophysical Field Methods class of 1984 for the use of their data; Bruce Bean, Jimmy Diehl, Thomas Friggins, Patrick Martin, and John Weymouth for helpful suggestions and encouragement; and Julene Erickson for typing the manuscript.

\section{REFERENCES}

Anonymous, 1924, Map of Fort Wilkins: Fort Wilkins Archives, Copper Harbor, Michigan.

Bornhorst, T. J., Rose, W. I., and Paces, J. B., 1983, Field guide to the geology of the Keweenaw Peninsula, Michigan: Dept. of Geol. and Geol. Eng., Michigan Tech. Univ., Houghton, MI

Carr, C., 1982, Handbook on soil resistivity surveying: Center for American Archaeology Press, Evanston, IL.

Tite, M. S., 1972, Methods of physical examination in archaeology: Seminar Press.

Zohdy, A. A. R., Eaton, G. P., and Mabey, D. R., 1974, Application of surface geophysics to groundwater investigations: U.S. Government Printing Office, Washington, D.C. 